QUADERNS DE FILOSOFIA VOL. III NÚM. I (20I 6): 27-49

ISSN: 234I-I4I 4 eISSN: 234I-3042 DOI: IO.7203/QFIA.3.I.8I42

César Moreno-Márouez

Universidad de Sevilla

\title{
Márgenes silentes. Palabra excedida y silencio inspirado (Hofmannsthal/Blanchot)
}

Recibido: 1/9/15. Aceptado: 6/3/16

Resumen: Contra los intentos de desalojar al silencio de la posibilidad de expresión, y de vaciar a la expresión de su propio silencio, el artículo propone como tarea para nuestro mundo contemporáneo el que seamos rastreadores de silencio. La tarea no es fácil, pues el silencio decisivo no se puede escuchar, sino que se halla atesorado en el interior de las palabras y obras como su última y más inspirada verdad. Para ello toma como guía la famosa Carta de Lord Chandos (Hofmannsthal), reivindicando su silencio-en-tránsito (excedido por una nueva experiencia de la riqueza desbordante de la realidad) y las reflexiones de Blanchot en torno a la relación entre silencio e inspiración. En la segunda parte, el artículo "rastrea", a modo de ejemplos "ejemplares", los silencios de A. López (El sol del membrillo) y el implicado en el secreto de "Rosebud" (Ciudadano Kane, Welles).

Abstract: Against attempts to vacate silence of the possibility of expression, and empty the expression of its own silence, this article proposes as a task for our contemporary world that we should be silence-trackers. This task is not easy, since the decisive silence cannot be heard, but it is treasured within the words and works as their last and most inspired truth. To that end, it is taken as a guide the famous Letter of Lord Chandos (Hofmannsthal), who claims his silence-in-transit (exceeded by a new experience of the overwhelming richness of reality), as well as Blanchot's reflections on the relationship between silence and inspiration. In the second part, the article "tracks", as "exemplary" examples, the silences of A. López (Dream of Light) and the one involved in the secret of "Rosebud" (Citizen Kane, Welles). 
Palabras clave: silencio, inspiración, expresión, Chandos, Hofmannsthal, Blanchot. Keywords: silence, inspiration, expression, Chandos, Hofmannsthal, Blanchot.

A Eugenio Silverio

Mucha poesia ha sentido la tentación del silencio. Porque el poema tiende por naturaleza al silencio. O lo contiene como materia natural. Poética: arte de la composición del silencio. Un poema no existe si no se oye, antes que su palabra, su silencio (VALENTE 2000, 42).

Pero, ¿para qué buscar de nuevo palabras, si he renegado de ellas? (Hofmannsthal 2008, 130).

\section{UN SILENCIO SILENTE}

$\mathrm{P}$ ROPONER LA TESIS de que, en virtud de una concepción superficial de la expresión y de una consideración presuntamente mistica o cuasimistica del silencio, a un lado estaría este, el silencio, como si no pudiera encontrar salida expresiva alguna (pues se trataría de un silencio insuperable), y al otro la expresión o la obra, como si no contuviera silencio interior alguno, supondría someter a ambos, tanto al silencio como a la obra, a una mortificación que reprimiría en aquél todo intento de expresión de lo que quizás atesorase, al tiempo que desvitalizaría y superficializaría a aquella, quedando entregada a su exterioridad, ya sin vida silenciosa “interior" alguna. Por todo ello, una propuesta como ésta —insisto, de separación entre expresión/obra y silencio o margen silente- lejos de ser obvia, resultaría sospechosa. La conocida tesis wittgensteniana según la cual de lo que no se puede hablar, hay que callar (WITTGENSTEIN 2003, 132) resulta más comprensible si se piensa que la precede la voluntad de un riguroso esclarecimiento formal que cree poder decidir acerca de lo que se puede y no se puede hablar. Se pretenda o no, el riesgo indirecto de aquel se-tiene-que-callar sería doble, pues podría alentar el allanamiento y superficialización de la expresión, al tiempo que, si hubiera de ser presentido, se coartaría o inhibiría casi regulativamente la emergencia de lo silente en ella, impidiendo recuperar los márgenes o fondos silentes de la experiencia y cercenando su, en tantas ocasiones, imperiosa vocación expresiva. 
Lejos de considerarlos extrínsecos o indiferentes entre sí, aquí, sin embargo, se considerará que silencio y expresión/obra se encuentran vinculados aunque solo fuese, en primer lugar, en honor a lo que de hecho es nuestro común deseo de expresión, en el arco inmenso que recorre desde nuestras aspiraciones expresivas más simples y cotidianas hasta los más excelsos procesos creativos. Que donde haya obra se haga silencio (o su deseo), y que donde haya silencio se haga obra (o su deseo). Tal vez podría ser ésta nuestra divisa. Respecto a la oportunidad expresiva del lenguaje, solo si de entrada se lo considerase fracasado (precisamente por alguna suerte de mística de lo silente en él, es decir, de lo que en él guarda silencio) o si se buscara previamente esclarecerlo y dominarlo analíticamente bajo condiciones rigurosas de forma y referencia, se podría pretender inhibir el esfuerzo expresivo o desalojar del lenguaje lo que en él inspira perturbadora y críticamente — pero también expresivamente- su margen silente. Quede constancia, pues, de que apelar al margen silente no debe ser entendido como si lo que aquí se quisiera dar a pensar fuese una suerte de redención de una mística silenciosa, expresamente por impotencia o limitación expresiva, siendo que el proceso creativo consiste precisamente, cuando es excelente, en llevar expresión al silencio y silencio a la expresión, ${ }^{1}$ doble llevar cuya urgencia y precariedad se aprecian eminentemente en los procesos creativos en los que juegan, se exceden y descuadran, fuera de cualquier tentación de rutina, intuición, significación y expresión. ${ }^{2}$ La separación estratégico-sistemática entre expresión y silencio pretendería dominar el lenguaje sobre todo por el desalojo técnico de sus márgenes silentes, fuese para a) consolidarlo en lo que presuntamente aparecería como "lo que puede ser dicho" legítimamente, de acuerdo a lo que cabe esperar de una expresión "sensata"; o bien para b) dejar libre una vía de silencio "místico" ya no desafiado por lo que cabría esperar de un lenguaje (desalojado estratégicamente de sus márgenes silentes) y, por tanto, a salvo de toda traición o contaminación por parte de "lo que puede ser dicho". De este modo, al mismo tiempo que se protegería al lenguaje de sus márgenes silentes, se liberaría a "lo místico" de tener que encontrar una expresión (en el lenguaje o en la obra, en general). Pero para entrever o atisbar los márgenes

${ }^{1}$ A este respecto, una incursión en un ensayo poético tan extraordinario como El mono gramático sería tan imprescindible como placentera (PAZ I988).

${ }^{2}$ Cfr. Moreno (2005). Uno de los núcleos críticos intrafenomenológicos decisivos en Jean-Luc Marion es, sin duda, la crítica a lo que denomina "penuria de la intuición", a la que se habría aferrado la filosofía, y en general el Saber, a fin de que el concepto o la significación pudiesen cubrir adecuadamente a la intuición. Cuanto más pobre la intuición, más eficaz el concepto. Contra el dictum kantiano de que las intuiciones sin concepto son ciegas, Marion dirá que, por lo que se refiere a los fenómenos saturados, dichas intuiciones son más bien cegadoras. Remito al lector a Marion (2008, 299 y ss.). 
silentes de lenguajes, obras y expresiones en general no es necesario apelar al exceso de "lo místico". Hay otros excesos más asequibles, si se me permite decirlo así, que hacen de aquellos márgenes algo más usual y cotidiano, y en este sentido, más ordinario y veraz, que nos recuerdan que no podemos forzar el acomodo entre intuición y significación a cambio de un empobrecimiento recíproco: significaciones allanadas, escuetas y bien ordenadas, para intuiciones de baja intensidad, y viceversa. Más allá de realidades y experiencias, digamos, menores, de poca intensidad, en las que se dan pero pasan desapercibidos los márgenes silentes, éstos aparecen en su radicalidad y plenitud sobre todo frente a la realidad desbordante, que tantos desafíos expresivos brinda y a tantos fracasos expone. ${ }^{3}$ Estamos, entonces, en el área del combate infinito de la poesía y, en general, del arte. Diré más: estamos en el área de combate de la poesía y del arte más acá o más allá de sus logros fehacientes y de su cuenta de resultados, en la poesía y el arte in statu nascendi.

Si bien hemos tomado como un primer motivo filosófico muy académico el conocido dictum wittgensteniano, en verdad, el tema del silencio se nos ha ido convirtiendo culturalmente en un asunto crucial — tema de nuestro tiempo- por motivaciones que no guardan relación solo con un genuino debate intrafilosófico. Entre otras razones, pienso en dos rasgos decisivos de nuestra época, uno de los cuales sería la inflación icónica y lingüistico-expresiva en las entrañas de nuestra ya monstruosa y "surfeadora" sociedad hipercomunicativa. Por otra parte, la atención rendida hoy al silencio, a sensu contrario, conecta con las resistencias que podría oponer el silencio al programa sistemático de exteriorización y transparencia de la vida de la conciencia que persigue no solo la neurociencia, en tanto que genuino paradigma científico de nuestro tiempo, sino también zonas decisivas de la cultura contemporánea.

Frente a lo que se espera de la superficialización y la exteriorización insisto, aliadas con el furor de la transparencia - parece claro que cualquier

${ }^{3}$ Hugo Mújica recoge un pasaje de Sloterdijk $(\mathrm{I} 992,92)$ que resulta muy pertinente. Dice Sloterdijk: "Que la percepción queda absorbida en los usos lingüísticos que nos son familiares es un tipo de mecanismo de protección ante el éxtasis, pues si uno meditase por su cuenta la radical idiosincrasia y el carácter extraverbal de la percepción, sería constantemente catapultado fuera de sí mismo, incluso, podría decirse, sería expulsado continuamente hacia las cosas en tanto cualquier cosa es una invitación a la excentricidad... Los sentimientos ante situaciones que abarcan aspectos totales, las miradas en derredor van más allá de toda posibilidad de expresión. Por esta razón, los sistemas sociales se organizan normalmente de tal modo que puedan subyugar la infinita plurivocidad de la percepción... pues de lo contrario surgirían más místicos de los que una sociedad puede integrar" (cit. por MújICA 2008, 227). 
silencio (o mejor aún, un silencio inspirado) no podría dejar de resultar incómodo y embarazoso por el retiro, oscuridad, profundidad o incertidumbre que solicita, al menos iniciales. Por supuesto, cuando pienso en un silencio inspirado no me refiero al silencio que puede ser impuesto en un silenciamiento: tapar o taparse la boca, hacer mutis, mandar orden de callar, retirar la palabra, amordazar, desanimar de hablar, decir o hacer, ciertamente. Este silencio obligado es uno de los grandes recursos de todo Poder. Pero aparte del silencio audible impuesto y de lo silenciado en él — que podría ser dicho si hubiese oportunidad y libertad suficiente-, bulle lo silente: lo que guarda silencio o lo atesora, cuando el silencio es inspirado, no siendo silencio necesariamente por no haber encontrado aún expresión, sino quizás sobre todo —es un matiz decisivo- por la espera(nza) silenciosa de expresión. No se trata aquí solo, así pues, del Poder que pretende imponer un silencio audible (todos callados, todo enmudecido, nada se escucha), sino de otros presuntos poderes que buscan el olvido de lo libremente silente, que es el silencio inaudito, el silencio que no se escucha, de sutilísimo acceso, pues no depende de una represión previa. Si hace ańos, Josep Llobera (I990, 139) se lamentaba de que el objeto de las Ciencias Humanas tuviese que hacer frente a un objeto parlante, pues ello supondría un fondo de subjetividad con el que cierta antropología cultural no sabría qué hacer, si esto ya se piensa de la palabra, ¡qué podría pensarse de los márgenes silentes, a qué olvido no se los habría de forzar ante los temores de un hundimiento de la episteme antropológica! Quizás la ya vieja crisis del humanismo no es/fue una crisis de la palabra (dicha o acallada), sino más bien de sus márgenes o tal vez de sus fondos silentes inauditos. El hombre "muere" cuando ya no puede guardar (atesorar) silencio.

Cuando se escriba la historia de las ideas de nuestro momento histórico se apreciará que el silencio fue una de estas "ideas" cruciales, y habrá que saber explicar por qué en algunas zonas del ambiente espiritual de nuestro tiempo se vivió tan de cerca la posibilidad del retiro en general y del silencio, que incluso se podría decir que se ha puesto de moda sin que, sin embargo, pueda ser cierto que se trate solo de una moda, ya que es una posibilidad esencial, como pocas, del ser humano, cuya verdad milenaria recorre todas las culturas. Sin embargo, parece acuciar más en nuestro tiempo — habría muchos testimonios al respecto- a cuyas prisa, dispersión, superficialidad, computabilidad y crispación el silencio inspirado buscaría responder con demora, recogimiento y profundidad, amplitud y distensión. 


\section{UN SILENCIO INAUDITO}

Ya he insinuado que este silencio que nos importa es quizás el más difícil de encontrar y, por supuesto, de ubicar objetivamente. Hablar del silencio cuando nada se escucha, o cuando después del sonido o del ruido acontece un enmudecimiento general, no es difícil. Experiencia — parecida - del silencio en, imaginémoslo, la solitaria vastedad del desierto, experiencia de la noche, en la que se aquietan los trajines diurnos, o de la casa vacía, sordomuda; incluso, en otro orden, silencio eminente, inolvidable y provocativo, por inesperado, que se hace cuando precisamente se espera escuchar música, como en 4,33, de John Cage... y resulta que nada se escucha. También memorables los paisajes silenciosos - y misteriosos - de Giorgio de Chirico. Se diría que hay muchas expresiones del silencio, de sus no, ya-no o aún-no. Tampoco es difícil explorar, como decía antes, los silencios obligados, impuestos, los silenciamientos incluso cuando ya no aparecen como tales.

Sin embargo, no me refiero a estos silencios, por lo demás fascinantes — como lo son el vacío y la ausencia-, silencios que se dejan escuchar y casi ver, de los que podríamos intentar levantar acta. No a estos silencios, que aparecen con nitidez en el espacio/hueco de una ausencia nítida, del pudor, de una prohibición o de un secreto casi objetivamente determinables. El silencio que aquí se busca no es tampoco un silencio originario o proto-silencio que pudiese demandar una nostalgia mítica o mística.

No estos silencios, digo, sino otro-silencio que debe presentirse precisamente mientras no hay silencio que pudiera ser constatado en o entre las palabras, o en las obras. El silencio silente inaudito no comparece patentemente en la ausencia de sonido o de lo legible, sino en medio o en los márgenes de lo que se deja escuchar o leer -o incluso ver. Sería absurdo, pues, querer encontrarlo objetivamente, del mismo modo como escuchamos palabras o las leemos, o incluso cuando, aunque nada escuchemos, sin embargo hay significación. El silencio que nos importa, silencio interior, vivo, viviente, invisible e inaudible, silencio de auto-afección exteriormente inconstatable, ${ }^{4}$ hay que presentirlo sobre todo, pues se expresa insinuándose, entretejiéndose, a veces camuflándose,

${ }^{4}$ Sin duda las enseñanzas a este respecto de Michel Henry resultan decisivas, en la medida en que rescatarían al silencio, y en general a la vida de la conciencia, de la coerción de una necesaria vocación exteriorizante-intencional. El silencio como "silencio-de" se deja objetivar, mientras que el silencio inaudible al que nos referimos jamás podría aparecer como tal en medio del mundo ni tendría por qué tener la referencia a un no-silencio que permitiera esclarecerlo. Este motivo de pensamiento, en un horizonte mucho más amplio y profundo, recorre toda la obra de Michel Henry, desde La esencia de la manifestación (cfr., como una aproximación breve y adecuada, Henrry 200i, 66 y ss.). 
como si de él solo pudiera haber resonancias difusas. Un silencio inaudito como la soledad invisible que se disimula cuando se está rodeado de gente. Se trata (ya se lo habrá adivinado sobradamente) del silencio-en-la-palabra, en la frase, en el lenguaje, en la obra, como un silencio marginal presentido. No es místico, sino un silencio de transición. Y si es importante este silencio, es porque es olvidado de tanto que "no se nota", y es tan grave la herida de los desprecios que experimenta, que hace de las significaciones y la expresión entidades muertas o zombificadas, o al menos sonambulizadas.

Pues bien, como en Bartleby y compañia el personaje de Enrique VilaMatas —o el propio Vila-Matas (2000)— quería ser un rastreador del "No" que proclama el abandono de la escritura literaria, podríamos asumir la tarea de ser rastreadores de silencios: pero no tanto en la ausencia-de-obra cuando ya "se ve" que ha dejado de haber obra, lo que después de todo no sería difícil, sino rastreadores de silencio precisamente en los olvidos-de-silencios-inauditos en el seno de la obra, o incluso fuera-de-obra; casi como si al mismo tiempo que escuchamos o leemos, debiésemos intentar des-escuchar, des-leer o des-obrar, pues solo en lo que (des)escuchamos, (des)leemos o (des)obramos podría ser presentido el silencio.

Se ha de precisar ya, para evitar posibles — aunque quizás improbablesequívocos, que este silencio inaudito al que me refiero no debería ser confundido con el que, con una expresión quizás inadecuada, podríamos llamar silencio "malo", no por reprimido, sino por estéril, no inspirado, que comparece cuando nada hay que presentir, debiendo entonces descubrirse en lo que escuchamos y leemos que-nada-se-dice en verdad -aunque el tímpano pudiese desmentirnos, aliado con nuestra casi automática maquinaria eidética: silencio de mera cosa, silencio de papagayo parlanchín, silencio de máquina parlante... Este silencio "malo" o al menos "demasiado pobre" no es siquiera silencio de finitud, resignado, consciente de su propio sufrimiento, de su combate, sino silencio de una palabra moribunda.

El otro silencio —el que nos importa— no se encubre por sí mismo ni se lo pretende expresamente, no aspira a separarse sino que, dándose, y pudiendo ser encontrado, sin embargo, lo olvidamos, dejando que lo que escuchamos o leemos lo eclipse. En este otro silencio el drama consiste en que nunca está simplemente ahí detrás o allí dentro, más o menos indiferente o inerte, de modo que su olvido resultase inocuo, sino que $d a$ vida, estrictamente, sin que pudiera confundirse lo silente en él —lo recordaba antes — con una mera significación, siendo como es más bien una animación o inspiración sentiente que da vida e intimidad a lo que decimos, escuchamos, escribimos o leemos.

Es más que razonable, imprescindible, que pudiera pensarse la posibilidad de una historia de este otro-silencio, que, insisto, debería ser distinguida de 
una historia de la represión de la expresión, en cualquiera de sus modalidades. Junto a esa historia aparecería ahora la de la represión del silencio. En este sentido, siempre hemos pensado mucho en torno a cómo hacer cosas con palabras, o cómo hacer palabras con cosas..., habiendo desatendido la posibilidad de cómo hacer palabras con silencios o silencios con palabras.

\section{Sufrir lo indecible... (Lord Chandos)}

El texto Ein Brief / Una carta, escrito por Hugo von Hofmannsthal en $1902^{5}$ es bien conocido, lo que me excusará de entretenerme aquí en comentar detalladamente su contenido. Enviada por Lord Chandos al filósofo Francis Bacon, narra en primera persona a) el enorme malestar que experimenta Lord Chandos cuando, según confiesa, le faltan las palabras para intentar describir el mundo, la realidad y, en general, unos acontecimientos y experiencias que antes encontraban simple y acomodada cabida en la expresión verbal; y b) al mismo tiempo, la exaltación de un desbordamiento de la experiencia, de modo que Lord Chandos se experimenta felizmente excedido e invadido por una riqueza y profundidad jamás anteriormente experimentadas. Ein Brief es un documento cuya brevedad no va en detrimento, en absoluto, de su intensidad y relevancia sintomatológica y proyectiva o "prospectiva". Sin duda, la carta puede ser abordada desde el punto de vista del documento patográfico, ${ }^{6}$ desde la circunstancia biográfica de un Hofmannsthal en plena crisis como escritor o poeta, a la búsqueda de nuevas posibilidades expresivas (drama, o incluso periodismo); o, como es muy frecuente, desde el entorno epocal de la Viena fin de siècle. Sin embargo, una lectura tan solo en este sentido más o menos "circunstancial" correría el riesgo de desatender el genuino motivo filosófico de la Carta, que aborda la/nuestra relación entre intuición, significación y palabra (o, en general, expresión), al tiempo que da testimonio de una ampliación descomunal de las posibilidades de la experiencia, que provoca que todo se tambalee y parezca perder pie. Podría creerse, en principio, que la carta avalaría cómodamente el man muss schweigen wittgensteiniano. Sin embargo, debería no

${ }^{5}$ Utilizaré la traducción más reciente, la de J. Muñoz Millanes (Hofmannsthal 2008), aunque hay disponibles al menos tres más (Vid. Bibliografía).

${ }^{6} \mathrm{~A}$ mi entender, dicha lectura sería legítima solo dentro de muy estrechos límites. En la medida en que se considere que el "mal" que aqueja a Lord Chandos tiene su razón de ser en una alteración o enfermedad psíquicas, de inmediato quedará devaluada la experiencia que narra. Tendrá validez solo en la medida y para quien se encuentre psicopatológicamente afectado. Sin embargo, la experiencia de Lord Chandos es intrínsecamente legítima desde su propia inmanencia fenomenológica. 
olvidarse que, como reconoce sorprendido el propio Chandos, aun renegando de las palabras, sigue usándolas, manifestando al final de la carta no su adhesión a un desesperado silencio, sino su esperanza en una nueva expresión. Así pues, contra su propia declaración, el silencio de Lord Chandos no sería terminal, sino de transición. Tal vez fuese cierto que a él le incumbiese callar, pero no así a generaciones venideras. Su lenguaje fracasa — si se me permite decirlo así-, a cambio de que no fracase su silencio, donde aparte de guardarse memoria de la posibilidad feliz (y esforzada) de la palabra (acallada), se rebosa intuición. En verdad, es como si hubiera de vaciarse el lenguaje para que pudiese tener más y mejor cabida. En la medida en que fuese un silencio más de malestar que de fracaso, la propia experiencia de malestar ya aporta la esperanza de una salida a la crisis. El silencio de Lord Chandos no quiere resolverse en un silencio sin palabras, sino que aún busca expresión y se preocupa al no encontrarla "a mano" o "ante los ojos". Se trata de un silencio, por tanto, dolido pero también inspirado en los márgenes silentes de los lenguajes que conocemos, instituimos $\mathrm{y}$, al mismo tiempo, rutinizamos, adocenamos, cretinizamos, ensoberbecemos... Sin embargo, como decía hace un momento, el reconocimiento del malestar es ya el comienzo de la sanación (PARDo 2008, 153). Después de todo, en la medida misma en que aumentasen las exigencias de nuestra experiencia, o en que ésta se viese excedida por desbordamientos o crecidas intuitivas (MARION 2008), lo razonable es que esa crisis se produjese (Rosset 2008), so pena de que se agravara lo que de por sí supone cotidianamente, si no la pobreza, sí al menos el carácter rutinario, simplemente "de andar por casa", de aspiraciones cortas y de bajo vuelo de nuestras palabras y conceptos.

En nuestra propuesta, el testimonio de Lord Chandos es el de una incursión en los márgenes o fondos silentes y lo que ello comporta. En dichos márgenes, las palabras y, en general, nuestros usuales medios expresivos quedan casi rotos, las frases, hechas añicos, y las significaciones sufren lo indecible — nunca mejor dicho- porque ya no aciertan a contener y domar la experiencia.7 Se lo puede apreciar con nitidez en grandes experiencias, pero también ante aparentes "naderías". Finalmente, sin embargo, Lord Chandos no parece resignarse al silencio inerte, sino que manifiesta en la Carta su anhelo por la venida de un nuevo lenguaje en el que todo eso que no podía ser dicho

${ }^{7}$ Dice Lord Chandos: "he perdido por completo la capacidad de pensar o de hablar coherentemente de ninguna cosa [...]. Experimentaba un malestar inexplicable por el simple hecho de pronunciar las palabras 'espíritu', 'alma', o 'cuerpo'. En mi fuero interno encontraba imposible expresar un juicio sobre los asuntos de la corte, lo que pasaba en el Parlamento o cualquier cosa que se os venga en mente. Y esto no por ningún tipo de miramientos [...] sino porque las palabras abstractas, de las cuales la lengua por ley natural debe hacer uso para sacar a la luz del día juicios de cualquier clase, se me desmigajaban en la boca igual que hongos podridos [...]. 
encontrase la oportunidad de una renovada expresión. No sueña con un más allá del lenguaje, sino con otro lenguaje... En la carta, los críticos o estudiosos suelen reparar incomparablemente más en la crisis de lenguaje que en el renacimiento que anuncia (p. ej., CACCIARI I982, 181), ahora sí, finalmente, en todos los sentidos, en una especie de ofensiva masiva contra el positivismo del xIX, a favor de —al unísono- una nueva expresión y una más amplia y profunda experiencia de la que, a mi juicio, ya no se trataría tanto de hacer una lectura al estilo romántico, ${ }^{8}$ cuanto más bien desde lo arribante a la altura epocal de 1902, a saber, desde la revolución expresiva en ciernes de un Proust o, sobre todo, un Kafka y, desde luego, de las vanguardias. Como bien dice Claudio Magris, el florecimiento fin-de-siècle

que hasta hoy no se ha podido valorar realmente en su grandeza, era —en gran parte - germen del futuro y no la pompa de la despedida. Pero el futuro que esa cultura presagiaba era el fin de toda una civilización, no solo austriaca sino europea, era la indefectibilidad de la despedida de un orden de valores, de una totalidad unitaria capaz de superar y abarcar la multiciplicidad de la existencia, de un sentido inmanente a los fragmentos dispersos del acontecer, de la verdadera vida (MAGRIS I993, 40)

La crisis espiritual de Lord Chandos provoca que lleve una vida vacía de espíritu y pensamiento (Hofmannsthal 2008, 128). Y, sin embargo, junto a este silenciamiento, demoledor por esterilizante, transcurre, para perplejidad del propio Chandos, un silencio inspirado que aún no tiene palabras... en el sentido de que el "no tener palabras" pudiera ser comprendido como una suerte de homenaje a lo expresivamente inconmensurable, de modo que en el

Con todo, esta infección se fue dilatando paso a paso como una herrumbre que devora cuanto queda a su alcance. También en la conversación familiar y casera todos los juicios que suelen emitirse a la ligera y con una seguridad de sonámbulos se me volvieron tan problemáticos [...] No conseguía captarlos ya con la mirada simplificadora de la costumbre. Todo se me fraccionaba y cada parte se dividía a su vez en más partes y nada se dejaba ya sujetar a un concepto. Las palabras flotaban libres a mi alrededor; se coagulaban en ojos que me miraban fijamente y a los que yo debo devolver la misma mirada fija: son torbellinos que me dan vértigo al contemplarlos, que giran sin cesar y a través de los cuales se arriba al vacío" (Hofmannsthal 2008, 126-8).

${ }^{8}$ Lord Chandos confiesa que "en una especie de embriaguez continua, todo lo existente se me presentaba como una gran unidad» (Hofmannsthal 2008, 124). Sin embargo, quizás fue un designio de la providencia divina que su espíritu «haya tenido que abismarse desde una presunción tan hinchada en estos extremos de desaliento y debilidad que constituyen ahora el estado permanente de mi ánimo" (125). Esta crisis, que pudiera parecer que solo afectase a la experiencia cuasi mística de la unidad del Todo, sin embargo, afectaba también a los "conceptos terrenales", de los que confiesa Chandos que le esquivaban, lo que le causaba "extraños tormentos del espíritu" (126). 
discurrir de la vida cotidiana y en sus márgenes silentes se reunirían los fracasos expresivos y un fluir de experiencias cuya intensidad quizás hiciese pensar que, a fin de cuentas, aquellos fracasos, motivados por estas experiencias, valieron la pena. ${ }^{9}$

Se diría que Lord Chandos se ha tornado demasiado exigente, por una parte, respecto a las posibilidades del pensamiento y del lenguaje, y, al mismo tiempo, extremadamente vulnerable. ${ }^{10}$ Confundido, se sorprende a sí mismo más acá de su propia impotencia, como traicionándola, o al menos olvidándola, y preguntándose: "Pero ¿para qué buscar de nuevo palabras, si he renegado de ellas?" (Hofmannsthal 2008, 130). Lo que siente Lord Chandos no es traducible simplemente en términos psicológico-morales. No se trata de mera simpatía o compasión hacia los seres... Es una experiencia más abierta, más metafísica.

En tales momentos, una criatura insignificante, un perro, una rata, un escarabajo, un manzano atrofiado, unas rodadas de carro que serpentean en la colina, una piedra cubierta de musgo llegan a importarme más que la bella y generosa amante en la más feliz de las noches. Esas mudas y, a veces, inanimadas criaturas se elevan hasta mí con una plenitud tal, con una presencia de amor tal [heben sich mir mit einer solchen Fülle, einer solchen Gegenwart der Liebe entgegen], que mis gratificados ojos son incapaces de detectar ningún punto muerto a mi

\footnotetext{
${ }^{9}$ Hofmannsthal $(2008,128-9)$ : "No me resulta fácil haceros ver en qué consisten estos buenos momentos [guten Augenblicken]; una vez más las palabras me abandonan en el instante crítico [die Worte lassen mich wiederum in Stich]. Pues es algo absolutamente innombrado y al mismo tiempo difícilmente nombrable [es ist ja etwas völlig Unbenanntes, und auch wohl kaum Benennbares] lo que en tales momentos se me anuncia colmando de una oleada desbordante de vida más alta, como se colma una vasija, cualquier apariencia de mi entorno cotidiano [mit einer überschwellenden Flut höheren Leben wie ein Gefäß erfüllend]. No puedo pretender que me comprendáis sin la ayuda de un ejemplo y me veo obligado a pediros indulgencia para la simpleza de los míos. Una regadera, un rastrillo abandonado en el campo, un perro al sol, un cementerio pobre, un tullido, una pequeña granja, todo esto puede llegar a convertirse en el recipiente de mi revelación [Gefäß meiner Offenbarung]. Cada uno de estos objetos, y los mil otros parecidos, sobre los cuales normalmente el ojo se desliza con natural indiferencia, puede de repente, en cualquier momento, que en modo alguno está a mi alcance suscitar, cobrar para mí un carácter sublime y conmovedor que la totalidad del vocabulario me parece demasiado pobre para expresar [ein erhabenes und rührendes Gepräge annehmen, das auszudrücken mir alle Worte $z$ arm scheinen]. Sí, puede que también a la determinada representación de un objeto ausente le corresponda la suerte inescrutable de ser llenada hasta los bordes por ese flujo suave e impetuosamente ascendente de sentimiento divino [mit jener sanft oder jäh steigenden Flut göttlichen Gefühles bis an den Rand gefüllt zu werden]".

${ }^{10} \mathrm{Al}$ escuchar ciertos conceptos y frases le invade la ira y todo le parece "sumamente indemostrable, falso, endeble". Pero — añade— su espíritu lo veía todo con una "inquietante cercanía" (Hofmannsthal 2008, 127).
} 
alrededor. Todo, todo cuanto existe, todo lo que recuerdo, todo lo que mis más confusos pensamientos tocan, me parece ser algo. Hasta la propia pesadez, el (en otras circunstancias) torpor de mi cerebro se me aparecen como algo; dentro de mí y a mi alrededor percibo un fascinante contrapunto infinito, y entre las materias que lo componen no hay ninguna en la que no sea capaz de transvasarme [hinüberfliessen]. Me parece entonces que mi cuerpo está hecho de meras cifras que todo me lo abren. O que podríamos acceder a una relación intuitiva con todo lo existente si empezásemos a pensar con el corazón [mit dem Herzen zu denken]. Pero cuando este peculiar hechizo me abandona, no puedo decir nada de él, ni tampoco explicar con palabras cabales en qué haya consistido esta armonía que me entreteje al mundo entero y cómo ha llegado a serme perceptible (HofmannSthal 2008, 131-2)

Lord Chandos describe su estado en términos de fermentación, burbujeo, bullicio, centelleo y pensar febril [eine Art fieberisches Denken] (HoFMannstHaL 2008, 134),

pero un pensar cuya materia es más inmediata, más fluida y más incandescente que las palabras [unmittelbarer, flüssiger, glühender ist als Worte]. Son también torbellinos, pero a diferencia de los torbellinos del lenguaje, no parecen conducir a lo sin fondo [ins Bodenlose], sino de algún modo a mí mismo y al más profundo regazo de la paz [in mich selber, und in den tiefsten Schoß des Friedens] (Hofmannsthal 2008, 134)

Y finalmente, Chandos anuncia el gran giro, pues, a pesar de todo, al fin se muestra que no va a renunciar a la expresión, o a la esperanza de la gran expresión. Los márgenes silentes encontrarán su salida, si acaso, quién sabe si su libertad, y puede ser que, en algún instante, su esplendor, pero será con otro estilo. Será necesario recurrir a un lenguaje —ya no el latín ni el inglés, desde luego- del que dice Chandos que no conoce ni una sola palabra; una lenguaje, sin embargo,

en la que las cosas mudas me hablan [eine Sprache, in welcher die stummen Dinge zuweilen zu mir sprechen] y en la que quizá un día en la tumba tendré que rendir cuentas a un juez desconocido (Hofmannsthal 2008, 135) 
Será difícil discriminar si la crisis expresiva sobreviene a Lord Chandos tras la exaltación experiencial de la intuición, o bien si dicha crisis, que le incita a guardar silencio, es la que finalmente si no ha causado sí al menos propiciado o favorecido la liberación de la intuición. Se ha de insistir reiteradamente en que el testimonio de Lord Chandos no es solo de pesar, malestar u opresión, sino también de exaltación. Toda la Carta está motivada no solo para narrar una experiencia de pérdida, sino también, y no menos, para decir que es finalmente imposible-callarse-para-siempre, para mantener viva una posibilidad futura de expresión, siquiera en primer lugar para que el reconocimiento del déficit expresivo pudiera servir de punto de partida, aunque solo fuese como llamada de auxilio. La confesión de Lord Chandos se convierte, tal vez, en el comienzo de la sanación (PARDo 2008, 153). El silenciamiento es de transición, como crisis expresiva, en camino a una palabra excedida por el silencio que la anima. Como ha reconocido con acierto Clément Rosset, lejos de apartarle de la realidad, la crisis de Lord Chandos le conduce a la verdadera realidad — junto a esa palabra excedida—. ${ }^{11}$

\section{RedENCión BLANCHOtiana DEL SILENCIO INSPIRADO}

Para comprender desde dentro la experiencia global (no meramente la crisis expresiva) de Lord Chandos, las indagaciones de Maurice Blanchot en torno a la obra y la ausencia de obra pueden aportar valiosas claves. Más allá de la pasividad que somete a Lord Chandos y le lleva a interpretar su experiencia como un padecimiento enfermizo, podría considerarse que está viviendo una crisis de tales dimensiones, a favor de una posibilidad de inspiración que está por llegar, que a Chandos le resulta insufrible mantenerse en ella sin palabras, sin expresión, sin obra. Mantenerse en el vértigo de la inspiración no es fácil, pues conducida a su extremo, la inspiración rechaza los lenguajes, las obras $y$, en general, los medios a nuestra disposición con los que creíamos poder esclarecer la experiencia. Sin embargo, por la vía de la pasividad, Chandos ha entrado en la inspiración con mayúsculas. De ese movimiento de penetración dice Blanchot que hay que defenderse

${ }^{11}$ Dice Rosset $(2008,191)$ que "lo que más me llama la atención de vuestra carta, tan interesante y tan conmovedora, es que os quejáis de una especie de pérdida de contacto con la realidad cuando, me parece, acabáis por el contrario de encontraros con ella de cara [...] Malestar que por lo demás yo creo pasajero, como creo pasajera vuestra decisión de no volver a escribir. Quien no encuentra ya palabras para designar las cosas de la realidad, es alguien que empieza a tener cosas nuevas que decir sobre ella”. 
si, pese a todo, se quiere hacer obra, como si solo se pudiese escapar de la esterilidad escapando de la omnipotencia de la inspiración, como si solo se pudiese escribir — ya que es necesario- resistiendo a la necesidad pura de escribir, evitando la cercanía de lo que se escribe, esa palabra sin fin ni comienzo que solo podemos expresar imponiéndole silencio. Este es el tormento mágico vinculado al llamado de la inspiración, que necesariamente se traiciona, y no porque los libros sean solo el eco degradado de una palabra sublime, sino porque solo se los escribe haciendo callar lo que los inspira, traicionando el movimiento que pretenden recobrar, interrumpiendo el "murmullo" (BLANCHOT I992A, 173-4) ${ }^{12}$

Este desafío de la inspiración explica la tentación del silencio a que se refería Valente, con quien comenzábamos. Antes propiamente de ver la luz, desde el momento de su concepción, ${ }^{13}$ gestándose en y desde el silencio, la obra debe acoger al mismo tiempo la necesidad interior de la expresión, de decir o de comunicar, a la que cree deberse, y que la conduce a la luz de los lenguajes, y la obligación de mantener un margen para el silencio del que surge y no la abandona.

Difícil tesitura: desear la expresión y, al mismo tiempo, quedar retenido por el exceso de lo que se habría de expresar. En los procesos escasamente creativos, el margen silente es menos exigente, pues la desproporción entre intuición y mención es menor (o aparentemente menor) ${ }^{14}$. Sin embargo, cuando la inspiración procede no solo, inmediatamente, de lo excesivo como tal, en su ser en bruto, sino de la propia palabra-excedida en cuanto tal palabra-excedida, de esta experiencia de quedar sobrepasadas nuestras palabras al uso, consolidadas, los márgenes silentes se tensan y profundizan. El boquiabierto se torna meditativo y comienza a "devanarse los sesos". De este modo, el hilo conductor es el propio lenguaje sobrepasado sea, en el caso de Chandos, por lo más nimio o por lo más grandioso sublime. En el fondo, como decía Ortega, ni Dios ni esta hoja de papel se pueden propiamente decir. Por eso la crisis expresiva de Lord Chandos abarca todos los niveles. Vuelve a resultar esclarecedor Maurice Blanchot cuando sostiene que

${ }^{12}$ Decía Valéry que "para esos hombres deseosos de inquietud y de perfección, una obra no es nunca una cosa acabada - palabra que para ellos no tiene sentido alguno-sino abandonada; y este abandono, que la entrega a las llamas o al público (ya sea por efecto del cansancio o de la obligación de entregar), es para ellos una especie de accidente comparable a la ruptura de una reflexión cuando la fatiga, la molestia o alguna sensación la anulan” (VALÉRY I980, 10).

${ }^{13}$ Una vez más, viene José Ángel Valente $(2000,10)$ en nuestra ayuda, al recordarnos —y es esencial para el silencio inspirado- que "el poema no se escribe, sino que se alumbra, y que comienza en la propia gestación”.

${ }^{14} \mathrm{Cfr}$. nuestra nota 2 . 
cuanto más pura es la inspiración más desprovisto está quien entra en el espacio al que ella lo atrae, en el que oye el llamado más cerca del origen, como si la riqueza que toca, esa superabundancia de la fuente, también fuese la extrema pobreza, fuese sobre todo la superabundancia del rechazo y lo convirtiese en quien no produce y yerra en el seno de una inacción infinita. Por lo tanto, el sentido común se equivoca al creer que el estado de aridez al que están expuestos los artistas más inspirados significa que, de pronto, la inspiración, esa gracia que es otorgada y retirada, les falta. Más bien hay que decir que hay un punto en el que la inspiración y la falta de inspiración se confunden, un punto extremo donde la inspiración, ese movimiento fuera de las tareas, de las formas adquiridas y de las palabras verificadas, toma el nombre de aridez, se convierte en esa ausencia de poder, esa imposibilidad que el artista interroga en vano, que es un estado nocturno, a la vez maravilloso y desesperado donde, quien no supo resistir a la fuerza demasiado pura de la inspiración, permanece en la búsqueda de una palabra errante (BLANCHOT I992A, 172)

En este sentido resulta tremendamente significativo que a la altura de 1902 se esté culturalmente a la expectativa de una revolución expresiva de proporciones culturales y espirituales descomunales, bajo la forma de las vanguardias... con fuertes innovaciones expresivas pero al mismo tiempo a cambio de importantes destrozos "gramaticales", en general, a los que por lo común solo valoramos en su superficie y no como la expresión radical de una búsqueda profunda. Pronto, hacia 1919, pero preparado desde mucho antes, irrumpirá la revolución poética del surrealismo. En este panorama de crisis y desafíos, en la década de los años 20 del siglo xx, el terreno estará maduro para un "golpe de mano" y una radical llamada al orden en cuestiones de lenguaje - en todo saber que quiera decir algo sensato sobre el mundo-, y será otra vanguardia sui generis, no precisamente en el terreno artístico, sino procedente de una zona de intersección entre Filosofía, Lógica y Ciencia, como es el positivismo lógico, la que lo dé. Uno de los lemas que orientarán el golpe neopositivista será, sin duda, la recepción no precisamente mística de aquel Wovon man nicht sprechen kann, darüber muß man schweigen... de Ludwig Wittgenstein.

En 1902, la Carta de Lord Chandos es radicalmente sintomática. En 1907 dirá Hofmannsthal (El poeta y este tiempo) que el inspirado está atento a todo y sufre sin descanso:

Sufre de tanto sentir las cosas, sufre de cada una y de todas a la vez, sufre con lo que tienen de singular, con la coherencia que las une, sufre con lo que en ellas es elevado, sin valor, sublime, vulgar; sufre como sus estados y sus pensamientos... No puede descuidar nada. Sobre ningún ser, sobre ninguna cosa, 
ningún fantasma, ningún fantasma nacido de un cerebro humano, puede cerrar los ojos. Es como si sus ojos no tuviesen párpados. No puede alejar ninguno de los pensamientos que lo acosan pretendiendo que pertenecen a otro orden, porque en el suyo cada cosa debe encontrar su lugar. En él todo debe y todo quiere encontrarse... Esta es la única ley a la que está sometido: no prohíbe el acceso a su alma a ninguna cosa (cit. por BLANCHOT I992A, 170) ${ }^{15}$

\section{El Silencio Recreado}

Un silencio invisible. El sol del membrillo

Como idea, debemos aprender a valorar en un sentido amplio el silencio inspirado, que ha de ser estratégicamente rescatado del mero horizonte lingüístico, y, en tal sentido, des-lingüistizado. Ya antes insistí en que el silencio no es nunca meramente un silencio-de-palabra. Guardar silencio, o ya de un modo creativo, contribuir a que pensemos en algo parecido a un silencio inspirado, invita a considerar una desactivación del trasiego comunicativo-informativo o la mera pragmaticidad de los resultados "objetivos" en el terreno expresivo, instruyéndose entonces el presentimiento de una profundidad o marginalidad en las que se entrecrucen profundidad, creatividad y - no temamos reconocerlo, siempre que la interpretemos adecuadamente- infracomunicación.

Decía que el desafío frente al silencio inspirado no se limita a un silencio de palabras o meramente lingüístico. Un ejemplo podría esclarecernos la situación experiencial del silencio inspirado. Pienso — casi diría que a título de una pedagogía de la inspiración y la obra- en el film El sol del membrillo, obra maestra de Víctor Erice, singularísima experiencia cinematográfica que casi mejor que ninguna otra penetra en los entresijos del proceso creativo. Hay al menos dos momentos de profundidad de lo que podemos llamar silencio inspirado, en un film que abunda en mostrar la experiencia de retirada del artista - lo que llamaba Valente $(2000,41)$ retracción - en un Aparte del Mundo o, en el caso de López, en su hortus conclusus. Silencio inspirado o creativo que se

${ }^{15}$ Doce años antes, encontramos la misma inquietud en Hofmannsthal, expresada en una carta del 18 de Julio de 1895 a Karg von Bebenburg: "Me gustaría sentir poderosamente el ser de todas las cosas y, zambullido en el ser, la verdadera significación profunda. Porque el universo entero está lleno de significación, es el sentido convertido en forma [...]. En todas partes, en todas las innumerables cosas de la vida, en cada una de ella, se expresa de modo incomparable algo que no puede captarse en palabras, pero que habla a nuestra alma. Y así el mundo entero es una palabra de lo inaprensible dirigida a nuestra alma o una palabra de nuestra alma dirigida a sí misma” (cit. por MuÑoz Millanes 2008, 18). 
manifiesta en que, aun reconociéndose que en ningún momento llegará a encontrar cabida la experiencia en la representación, sin embargo, no se abandona el trabajo expresivo.

Primer Silencio-de-Presencia: un silencio — según suele utilizarse hoy la expresión- in progress. Jamás se lo podría encontrar en el lienzo, lo que viene a conceder precisamente máxima relevancia al film de Erice. El silencio inaudiblelinvisible coincide con la plenitud de la estancia del aqui del pintor, que no capta quien creyese que esa proximidad o inmediatez podría ser sustituida, justamente de cara a la obra, por, por ejemplo, una fotografía o por cualquier imagen del membrillero. Comoquiera que le visitan unos admiradores orientales, al comentario relativo a que muchos pintores llevan a cabo su trabajo a partir de una fotografía, López confiesa que en verdad el pintar no es sino la excusa perfecta — silenciosa - para estar allí largo tiempo de disfrute, junto al membrillero, su luz, etc. Lo que le importa, dice, no es el resultado, sino el estar-junto-al membrillero.

Por otra parte, un silencio de abandono, pero silencio ya repleto de expresión. Tras diversas experiencias desanimantes — demasiados cambios de luz, atmosféricos, en el propio devenir del membrillero, etc., como para que pudiese culminar felizmente el intento-de-obra, entiéndase, como obra acabada-, el pintor desiste, deja de pintar en dos ocasiones. A la pregunta de si acaso ha fracasado cuando deposita en el sótano de su casa el lienzo inacabado, quizás habría que responder que con ese gesto de humildad se nos ha recordado que el pintor no ha sucumbido al error al que habría de exponernos casi forzosamente la obra acabada (presuntamente acabada), como si fuese legítimo hacernos creer que la pintura de un lienzo podría atrapar la fuente de inspiración que ha convocado al pintor. Al enviarla al sótano — una forma de mantenerla en otro logos, en otro "a buen recaudo", como quizás le gustaría decir a Heidegger-, Antonio López nos invita a pensar que es en lo no-visto, en lo invisible, en el silencio de la pintura "silente" donde reside su verdad última más profunda..., porque lo que se trata de aprender es que lo que está en juego es irreductible a lienzo como una suerte de resultado visible y aparentemente feliz...

Esta es una experiencia clave para una historia del silencio, en la medida en que - como leeremos en El espacio literario, de Blanchot- nunca como en nuestro tiempo se ha sentido tan creativamente esa diferencia entre lo inacabado y lo acabado. El saber que hemos alcanzado acerca de los márgenes silentes ha aportado a nuestro tiempo una profundidad que otros siglos conocieron, ciertamente, pero que con seguridad no llegaron a pensar tan a fondo como el nuestro. En un pasaje memorable de El espacio literario se refiere Maurice Blanchot a la esperanza que 
protege al artista cuando, al querer hacer obra, pero no queriendo traicionar lo que la inspira, intenta conciliar lo inconciliable y encontrar la obra allí donde debe exponerse a la inacción esencial. Experiencia atormentada, que solo se puede proseguir bajo el velo del fracaso; $y$, sin embargo, a pesar de que la experiencia es el movimiento infinitamente arriesgado que no puede triunfar, a lo que sale de ella lo llamamos triunfo, a ese tormento lo llamamos felicidad, y esa pobreza árida se convierte en la plenitud de la inspiración: esa desesperación laboriosa, infatigable, es la suerte o la gracia de un don sin trabajo. Un artista nos dice lo que el artista encuentra en el seno de la experiencia: "Mis cuadros no tienen valor", "Yo, como pintor, nunca significaré nada importante, lo siento absolutamente". Esta es la verdad de la experiencia: hay que perseverar en el espacio de este no tienen valor, mantenerse preocupado por la realización y el derecho a la perfección, soportando el desamparo de un fracaso irremediable. Solo que para nosotros este fracaso se llama Van Gogh y el desamparo se convierte en el resplandor, la esencia misma del color.

Lo esencial de esta experiencia consiste en que, durante largo tiempo, las obras han pasado por ella, pero ignorándola o dándole un nombre que la disimulaba [...]. Hoy ya no es así. La obra ya no es inocente. Sabe de dónde viene. O, al menos, exige en esa búsqueda del origen, estar cada vez más cerca del origen, sostenerse en esta cercanía y mantenerse allí donde se juega la posibilidad, donde el riesgo es esencial, donde amenaza el fracaso; y hacia allí empuja al artista, lejos de ella y lejos de su realización. Esta experiencia se ha vuelto tan grave que el artista la continúa sin fin, y por desesperación, y al mismo tiempo preocupado por lo esencial, la muestra a la luz del día, trata de expresarla directamente o, en otros términos, hacer de la obra un camino hacia la inspiración, lo que protege y preserva la pureza de la inspiración, y no de la inspiración un camino hacia la obra.

Que esta marcha sea lógicamente errónea no significa nada, porque la necesidad de este error, el hecho de que ella es aparentemente sin salida y que no es menos exigencia extrema, este carácter de exigencia sin salida es el que obliga al artista a no desviarse de ella y a soportar misteriosamente la desmesura. Pero hay otra dificultad que prueba más profundamente su error. (...).

Tal vez, desde el instante en que la experiencia rompe la intimidad y busca revelarse, tal vez ya esté inmediatamente perdida. Tal vez solo busca develarse para volverse soportable, para aligerarse, y "disminuirse" (...). El secreto debe ser roto. La oscuridad debe entrar en la luz y hacerse luz. Lo que no puede decirse debe, no obstante, oírse: Quidquid latet apparebit, todo lo que está oculto debe aparecer (BLANCHOT I 992A, 175-6) 
Así pues, el silencio inspirado puede preceder a la obra, que comienza a gestarse en él, pero también, y no menos decisivamente, puede ser provocado por la obra misma. Lo que se nos enseña en $E l$ sol del membrillo no podía sino culminar no con el fracaso, sino, en verdad, con el triunfo inaparente de la obra inacabada.

\section{Silencio y existencia. Rosebud}

Decía al comenzar que podríamos convertirnos en rastreadores de silencio, de ese silencio — entre otros, ciertamente- que hemos llamado aquí inspirado y que hemos creído poder localizar en unos espacios a modo de márgenes silentes. Sin embargo, no se trata únicamente de que esos silencios sean solo rastreados. Tan atacado y mistificado se encuentra el silencio en general y, concretamente, en su máxima expresión — la existencial—, que es preciso que los silencios inspirados sean recreados, pudiendo para ello recurrirse a las mejores zonas experimentales, artísticas y de pensamiento de nuestro entorno cultural. También la historia de la idea de silencio habrá de saber dar ajustada cuenta de cómo una época se esforzó en sentir, pensar y expresar... el silencio como tal: no lo que bulle en el silencio, sino el silencio mismo, la verdad pura o formal del margen silente.

Creo que Ciudadano Kane podría ser aducido como ejemplo de ese esfuerzo expresivo a favor del margen silente del silencio inspirado. Este silencio se muestra en el film de modo indirecto, bajo la modalidad, ya elocuente y muy temática, de algo desconocido, enigmático, misterioso, que debe ser descubierto. Desafío tremendo para un periodista cuya labor es acercar el foco de la noticia o de la información todo lo posible a las luces y taquígrafos de las imágenes y las palabras. Pues bien, el silencio de Rosebud supone el máximo bloqueo: resistencia-de-trascendencia frente al trasiego de la información, la comunicación y la transparencia a los que me referí al comienzo, cuando dije que ellos motivaban que el silencio se estuviese convirtiendo en tema de nuestro tiempo. Un legado —el de Rosebud — de silencio, sin duda, y de desconocimiento. Pero lo decisivo es tanto que en el mundo narrado, el de Kane, nadie sabrá lo que, fuera de la mera referencia y fuera del significado, suponía Rosebud para el niño que tuvo que abandonar su familia, etc., pues el trineo será pasto de las llamas; digo que tan decisivo es eso como que el genio de Orson Welles nos haya encumbrado a un punto de vista casi "divino", recordándonos que la verdad de la existencia no está en los hechos y dichos, sino en los márgenes silentes... Rosebud surge de allí, del margen, y se convierte en la última palabra de Charles Foster Kane. Escuchamos Rosebud, el periodista indaga continuamente sobre Rosebud, pero su verdad habrá de quedar silenciada por la muerte de Kane. 
Para nosotros, la lección estriba en esa exigencia de mantener a buen recaudo, sin banalizarlo, sin olvidarlo, sin pisotearlo, el margen silente de nuestras vidas, de nuestros pensamientos, incluso el margen silente de nuestra época...

\section{Un silencio inspirado, redimido}

Hofmannsthal, Erice, Welles o Blanchot. Cuatro ejemplos de maestros ejemplares en la producción y recreación de esta estética y ética del silencio inspirado, que lo rastrean allí donde creen poder encontrarlo y que no rehúyen, sino que persiguen crearlo o recrearlo — si fuese suficiente decirlo así-, justo en la medida en que por esa recreación del silencio se nos trae la memoria de la fuerza de la disidencia — espontánea o involuntaria— de los márgenes silentes, de los que todos sabemos y que con tanta desidia olvidamos.

Al hacer la crítica de la biografía de Mallarmé llevada a cabo por Henri Mondor, Blanchot $(\mathrm{i} 977,115)$ alaba el trabajo realizado, llamando la atención sobre que "existe un silencio de una especial cualidad que impide toda esperanza de su disipación, y que es tanto más notable y misterioso en cuanto que no establecido deliberadamente por secreto alguno". Tras recordar que Mallarmé no hizo nada en especial por ocultarse, añade Blanchot que

¿de dónde viene este enigma, cómo, habiendo hablado mucho más que otros, puede dar la impresión de haber callado tan profundamente?

La historia del silencio de Mallarmé, caso de hacerse, tendría, a falta de un sentido ejemplar, el interés de una mirada que escudrińa una ausencia, una profundísima realidad que solo se abriría al conocimiento en el hecho mismo de no poder ser conocida (BLANCHOT I977, 115)

Es necesario que se produzca mucho silencio inspirado, en sí mismo, en cada obra, y en pensadores que nos recuerden el exceso que desborda a las palabras, los lienzos, las noticias, las biografías o las obras.

Recuerda Blanchot cómo en el encuentro del joven Artaud con el editor Jacques Rivière, a quien quería dar a conocer sus poemas, Rivière no quedó satisfecho con dichos poemas al tiempo que, sin embargo, le atraían las explicaciones de Artaud sobre la importancia que concedía él mismo a su obra. A raíz del intercambio epistolar que mantuvo con Artaud, Rivière decidió no publicar los susodichos poemas, pero sí las cartas escritas "en torno a esos poemas no publicables". Dice Blanchot:

Poemas que [Rivière] consideraba insuficientes e indignos de ser publicados dejan de serlo cuando están complementados por el relato del experimento de 
su insuficiencia. Como si lo que les faltara, su carencia, se volviese plenitud y perfección por medio de la expresión abierta de esa carencia y el ahondamiento de su necesidad (Blanchot I 992B, 43)

Una carta, de Hugo von Hofmannsthal, se parece mucho a lo que dice Blanchot respecto a Artaud. Todo consistiría en hurgar en los márgenes silentes con respeto y veneración suficientes; no se trata de un trabajo analítico ni se ha de llevar a cabo con un escalpelo ni como un ejercicio genealógico de venganza ni como una mera práctica hermenéutica de justificación. En aquellos márgenes, la palabra excedida se encuentra con el silencio inspirado. 


\section{BiBLIOGRAFÍA}

Blanchot, M. I977, "El silencio de Mallarmé”, en Falsos pasos, Valencia: PreTextos, 111-8.

Blanchot, M. I992A, El espacio literario, Barcelona: Paidós.

Blanchot, M. і992B, "Artaud", en El libro que vendrá, Caracas: Monte Ávila, 43-9.

Cacciari, M. I982, Krisis. Ensayo sobre la crisis del pensamiento negativo de Nietzsche a Wittgenstein, México: Siglo xxi.

Henry, M. 200 i, Encarnación. Una filosofía de la carne, Salamanca: Sígueme.

Hofmannsthal, H. Von 2008, "Una carta”, en Una carta (De Lord Philipp Chandos a Sir Francis Bacon), Valencia: Pre-Textos, 119-35 [trad. de J. Muñoz Millanes].

Hofmannsthal, H. Von i978, "Una carta”, Hora de poesía, 94-96, 107-16 [trad. de E. Volkening].

Hofmannsthal, H. Von 1996, Carta de Lord Chandos, Murcia: Colegio Oficial de Aparejadores y Arquitectos Técnicos de Murcia [trad. de J. Quetglas].

Hofmannsthal, H. Von 200I, "Una carta", en Carta de Lord Chandos y otros textos en prosa, Barcelona: Alba, 31-51 [trad. de A. Diéterich].

Llobera, J. I990, La identidad de la antropología, Barcelona: Anagrama.

Magris, C. I993, El anillo de Clarisse. Tradición y nibilismo en la literatura moderna, Barcelona: Península.

Marion, J.-L. 2008, Siendo dado. Ensayo para una fenomenología de la donación, Madrid: Síntesis.

Moreno, C. 2005 , "Dinámica de la intuición. Reflexiones sobre la donación fenomenológica y el fin del conocimiento en Husserl (con una incursión en el caso-Chandos)", en Moreno, C. y Mingo, Alicia Ma (eds.), Signo, Intencionalidad, verdad. Estudios de Fenomenología, Sevilla: Universidad de Sevilla, 57-70.

Muñoz Millanes, J. 2008, "Introducción”, en Hofmannsthal, H. Von 2008, 11-59.

Pardo, J.-L. 2008, "Desde Londres, a 5 de Noviembre de 1603)", en Hofmannsthal, H. Von 2008, 139-59.

PAZ, O. 1998, El mono gramático, Barcelona: Seix Barral.

Rosset, C. 2008, "Hablar por hablar", en Hofmannsthal, H. Von, Una carta (De Lord Philipp Chandos a Sir Francis Bacon), cit. supra, 189-97.

Sloterdijk, P. i 992, El sol y la muerte, Madrid: Siruela.

Valente, J. A. 2000, “Cinco fragmentos para Antoni Tàpies”, en Obra poética 2. Material memoria (1977-1992), Madrid: Alianza Editorial, 41-6. 
VALÉRY, P. I980, El cementerio marino, Madrid: Alianza Editorial.

Vila-Matas, E. 2000, Bartleby y compañia, Barcelona: Anagrama.

Wittgenstein, L. 2003, Tractatus logico-philosophicus, Madrid: Alianza Editorial. 